\title{
Produção de material didático para o ensino de História: uma experiência de formação
}

\author{
Production of teaching material for the teaching of \\ History: an experiment in teacher training
}

\section{Nadia Gaiofatto Gonçalves}

Doutora em Educação pela Universidade Federal do Paraná (UFPR), professora adjunta III da Universidade Federal do Paraná (UFPR), Curitiba, PR - Brasil, e-mail: nadiagg@ufpr.br

\section{Resumo}

Neste trabalho discute-se uma iniciativa de formação inicial e continuada de professores de História para a educação básica, o Grupo de Estudos Ensino de História (GEEH), que agrega graduandos do curso de História e professores em exercício. São abordados os estudos e produções desenvolvidos em 2009, quais sejam: discussão teórico-metodológica sobre o uso didático de documentos, no primeiro semestre, e desenvolvimento coletivo de um dossiê didático temático, no segundo. A proposição do GEEH funda-se em especial nas proposições de Suzanne Citron, Gemma Traveria, Philippe Perrenoud e Pierre Bourdieu, respectivamente sobre o ensino de História e formação continuada de professores. Para a produção do material didático, a obra de Gemma Traveria, intitulada Enseñar a pensar 
historicamente: los archivos y las fuentes documentales en la enseñanza de la historia (2005) foi fundamental. O tema escolhido pelo grupo foi Ditadura Civil-Militar, com ênfase no Paraná, por várias razões, entre as quais, sua relevância, a preocupação em associar sua problematização aos âmbitos regional e local e a relativa facilidade de acesso a bibliografias e documentos. Foram identificados documentos relativos ao tema no Arquivo Público do Paraná e na Biblioteca Pública do Paraná. Cada participante escolheu alguns deles e desenvolveu roteiros didáticos, que foram apresentados e discutidos no grupo, constituindo-se várias versões, até serem aprovados. Ao todo, foram elaborados vinte roteiros didáticos, abrangendo diferentes dimensões do tema, como política, economia, cultura, educação, repressão, movimento estudantil, entre outros. Esse dossiê será disponibilizado no site do GEEH.

Palavras-chave: Ensino de História. Produção de material didático. Uso didático de documentos. História do Paraná. Ditadura Civil-Militar.

\section{Abstract}

This study discusses an initiative for the early and ongoing training of teachers of history in basic education, the Study Group for the Teaching of History (GEEH), which includes History course graduates and teachers who are already active in their profession. The study deals with studies and activities undertaken in 2009, including a theoretical and methodological discussion on the use of documents in teaching, in the first semester, and the collective development of a dossier about teaching themes, in the second semester. The intentions of the group are based especially on the proposals of Suzanne Citron, Gemma Traveria, Philippe Perrenoud and Pierre Bourdieu, respectively, concerning the teaching of history and the ongoing training of teachers. For the production of the teaching material, extensive use was made of the work of Gemma Traveria entitled Enseñar a pensar historicamente: los archivos y las fuentes documentales en la enseñanza (Teaching how to think historically: archives and documental sources in teaching history) (2005). The theme chosen by the group was the Civil-Military Dictatorship, with special emphasis on Paraná State. This subject was chosen for several reasons, including its relevance, concern that the subject should be viewed in a regional and local context and the relative ease of access to bibliographies and documents. Pertinent documents were identified at the Public Archives of Paraná State and the state's Public Library. Each participant chose some of these materials 
and developed teaching scripts, which were presented to the group and discussed, resulting in a number of versions being developed prior to approval. In total, twenty scripts were prepared covering different dimensions of the theme such as politics, economics, culture, education, repression, student movements, etc. This dossier was made available on the Groups website and the group intends to publish it for distribution to state schools.

Keywords: Teaching of History. Production of teaching material. Use of documents in teaching. History of Paraná State. Civil-Military Dictatorship.

\section{Introdução}

O Grupo de Estudos Ensino de História $\left(\mathrm{GEEH}^{1}\right)$ foi criado em 2007 e surgiu na confluência de demandas por maior integração entre a universidade e a escola, incentivada pelas Pró-Reitorias de Graduação e de Extensão da UFPR. O GEEH busca, assim, contemplar simultaneamente um vínculo com a comunidade externa à universidade; no caso, professores em exercício, e destes com licenciandos, dessa ou de outras instituições de ensino superior. Em geral, os participantes do grupo são graduandos de História e de Pedagogia, e professores da educação básica. Contudo, no semestre de desenvolvimento deste material não houve inscrições de graduandos da Pedagogia.

No GEEH considera-se que o ensino de História teve um percurso marcado pela história oficial e política, e por seu papel na formação do cidadão, com diferentes compreensões, ao longo do tempo, a respeito dessas funções. Em especial a partir dos Parâmetros Curriculares Nacionais estão sendo revistos o papel e as atribuições da História como disciplina escolar, e o diálogo com a produção historiográfica e pedagógica se faz necessário, na busca de discussão, compreensão e proposição de caminhos e possibilidades para seu desenvolvimento na escola.

1 Coordenação do GEEH: Nadia G. Gonçalves. 
Nesse sentido, o GEEH, na forma como foi proposto, permite a convivência, a leitura e a proposição de diferentes olhares sobre os temas e textos selecionados pelo grupo, contribuindo assim para a formação inicial e continuada dos participantes. Ao mesmo tempo em que graduandos podem ser beneficiados com essa oportunidade de estudo e troca de experiência com docentes em atuação, os professores da educação básica têm facilitado o acesso e a reflexão em relação ao conhecimento produzido academicamente, pensando-se em sua formação continuada. Nesse sentido, o objetivo geral do GEEH foi estabelecido como de "discutir fundamentos teórico-metodológicos do ensino de História e possibilidades de usos de materiais didáticos e documentos no ensino de História para o Ensino Fundamental e Médio".

Especificamente neste trabalho, o propósito é apresentar e discutir a produção coletiva de um dossiê didático temático, com o tema Ditadura Militar no Paraná, que foi desenvolvido no decorrer de $2009^{2}$. Para tanto, o artigo está organizado da seguinte forma: apresentam-se fundamentos teórico-metodológicos que subsidiam as atividades do grupo e a construção do dossiê temático; a metodologia adotada para a elaboração do dossiê; e atividades didáticas desenvolvidas no dossiê, buscando-se discutir a aplicabilidade nesses materiais, dos pressupostos teórico-metodológicos enunciados.

\section{Fundamentos teórico-metodológicos do Grupo de Estudos Ensino de História}

A criação do GEEH funda-se na necessidade de refletir a respeito da função da escola e do ensino de História na escola, no mundo contemporâneo, e dos dilemas que envolvem essas questões, trazidos para a especificidade local. Suzanne Citron (1990) já detectava na França uma

\footnotetext{
${ }^{2}$ Este artigo é uma versão estendida de trabalho apresentado no XV Encontro Nacional de Didática e Prática de Ensino (Endipe), realizado na UFMG, Belo Horizonte, em abril de 2010.
} 
crise do sistema escolar, articulada à desestruturação social e à perda da memória, que resultava em processos de marginalização e violência. Embora tratando de outra sociedade e tempo, é possível perceber situação semelhante no Brasil. Parte do problema, a autora remete à escola:

o prolongamento generalizado da escolaridade obrigatória criou uma situação antropológica sem precedente: as sociedades que inventaram a escola, há mais de dois mil anos, reservavam a cultura escolar a uma minoria de privilegiados; pede-se hoje a todos os jovens que passem o seu tempo a instruir-se até aos dezasseis anos. Enquanto o estudo, para as aristocracias antigas, era lugar de trabalho desinteressado, elevação da alma, busca sem constrangimento, a escola ocidental, ao generalizar a todos a herança escolar pretendeu, por um lado, fazer de todos os jovens os herdeiros da paidéia, da memória cultural da elite e, ao mesmo tempo, decidir do seu futuro profissional e social, segundo as normas do seu insucesso ou sucesso. Contradição insuperável e projecto impossível mascarado pelo discurso dum pseudo-igualitarismo que se exprime na fórmula ambígua de "a igualdade de oportunidades" (CITRON, 1990, p. 112).

Citron ainda discute a adequação do currículo escolar, organizado no século XIX, às necessidades das sociedades contemporâneas:

hoje em dia, num mundo revisto e modificado pela ciência pós-newtoniana, que linguagens, que chaves, que estrutura de saberes utilizar para dar aos jovens, a partir da sua diversidade familiar e social, os meios para descodificarem o mundo que os rodeia, para traçarem as suas referências numa cultura tecnológica, audiovisual, informática? Como representarmos o universo em categorias contemporâneas e não segundo as do século passado? O fim proclamado da escola é transmitir "o" conhecimento e "o" saber. Poderemos fazê-lo sem nunca nos interrogarmos acerca do que se transmite? (CITRON, 1990, p. 113).

O encaminhamento proposto é priorizar o sujeito, disponibilizar-lhe "os meios para construir a sua pessoa, para compreender o mundo em que vive, para se descobrir passo a passo na imagem que os outros lhe 
dão e no seu próprio narcisismo, para aprender a comunicar, criar, lutar, construir" (CITRON, 1990, p. 117).

Em relação a essa problematização, Gemma Traveria (2005) discute o uso de fontes primárias no ensino de História, sugerindo encaminhamentos para essa prática pedagógica, compreendida como contribuição para a superação de dilemas colocados para a escola e para o ensino de História na atualidade.

Tratando-se ainda da superação desses dilemas, é preciso abordar a formação de professores. Philippe Perrenoud (2001, p. 163) propõe uma discussão sobre:

[...] como conceber uma formação deliberada do habitus profissional, orientada por objetivos, mas aberta, respeitosa à pessoa, que não retroceda nem à "instrução disciplinar", nem ao simples aprendizado por tentativas e erros, no âmbito de estágios tradicionais ou de outros "momentos de prática".

Como habitus, o autor utiliza o referencial de Pierre Bourdieu, remetendo assim às "disposições adquiridas pela experiência, logo, variáveis segundo o lugar e o momento" (BOURDIEU, 2004, p. 21). Para ele, o habitus, sendo

[...] produto da incorporação da necessidade objetiva, [...] necessidade tornada virtude, produz estratégias que, embora não sejam produto de uma aspiração consciente de fins explicitamente colocados a partir de um conhecimento adequado das condições objetivas, nem de uma determinação mecânica de causas, mostram-se objetivamente ajustadas à situação. [...] [Os agentes] fazem, com muito mais freqüência do que se agissem ao acaso, "a única coisa a fazer". Isso porque, abandonando-se às intuições de um "senso prático" que é produto da exposição continuada a condições semelhantes àquelas em que estão colocados, eles antecipam a necessidade imanente ao fluxo do mundo (BOURDIEU, 2004, p. 23).

No sentido anteriormente apresentado é que Perrenoud (2001, p. 170) defende a constituição intencional de um habitus profissional. $\mathrm{Na}$ 
medida em que haja o reconhecimento de que o habitus é parte inerente da ação pedagógica, podem-se propor estratégias para seu aperfeiçoamento. $O$ autor sugere duas, que são complementares: 1) transformar as conduções de sua prática para induzir uma evolução de seus hábitos; 2) favorecer a tomada de consciência de seu funcionamento e a passagem de certas ações sob o controle de conhecimentos procedimentais e da razão.

Perrenoud também elenca mecanismos suscetíveis a favorecer a tomada de consciência e as transformações do habitus, entre os quais estão a prática reflexiva e a mudança nas representações. Deve-se lembrar que para Bourdieu o habitus é ao mesmo tempo coletivo e individual, e esse autor enfatiza sua característica de incorporação no agente, de tal forma que se torna o próprio agente, em um processo de interiorização, reproduzindo internamente nele as estruturas externas do mundo. Contribui significativamente para a reprodução da ordem social, na medida em que esta não pode se dar sem a adesão, o reconhecimento e mesmo a ação dos agentes e instituições envolvidas; porém, esse processo se dá de forma sutil, em geral inconsciente por parte dos agentes.

A constituição do habitus implica uma dialética entre ele e as significações prováveis percebidas pelo agente, no sentido de que este tenderá a observar na realidade elementos que reconhece e pensa compreender, resultando em práticas que reforçam essa visão de mundo. Bourdieu denomina essa situação como "causalidade do provável”, uma vez as disposições incorporadas levam o agente a limitar-se ao que entende como possível, considerando seu lugar no mundo.

Nesse sentido, as discussões e reflexões desenvolvidas no GEEH contribuem positivamente para a constituição do habitus profissional e para a tomada de consciência e transformação da prática dos professores, no que diz respeito à sua ação docente e ao ensino de História, na medida em que o grupo de estudos se propõe a promover uma formação de fato continuada, e não apenas pontual.

Especificamente quanto ao uso de documentos no ensino de História, entende-se que, mesmo na abordagem mais tradicional, era possível encontrar trechos de fontes primárias em livros didáticos. Contudo, 
o que mudou ao longo do tempo foi o entendimento quanto ao olhar e à utilização que se deve lançar a esses documentos, a partir da discussão, no âmbito historiográfico, a respeito da construção da História, do papel do historiador e da concepção de documento.

Para a condução dessa discussão no grupo de estudos, parte-se de alguns pressupostos, a saber:

1) de que há clareza, por parte do professor, sobre não haver uma verdade absoluta a respeito dos eventos e fatos históricos, mas versões possíveis, não necessariamente excludentes entre si. Embora esse primeiro pressuposto pareça óbvio, é comum haver dificuldade em enunciar e trabalhar essa concepção de História, permeando os conteúdos em sala de aula;

2) de que documentos são registros parciais, limitados, de olhares possíveis a respeito de práticas e eventos históricos;

3) de que as fontes possíveis para a História abrangem, além de registros oficiais, objetos, registros orais, produções escritas não formais, iconografia, enfim, quaisquer vestígios a respeito do fato ou tema a ser problematizado e explicado/compreendido historicamente;

4) de que o ensino de História deve efetivamente superar radicalismos, desde o conteúdo pelo conteúdo, às habilidades e competências, ou ainda à militância. A compreensão aqui é de que desenvolver habilidades e competências é fundamental, mas que somente isso, sem conhecimento do conteúdo específico, é um aprendizado limitado; e a formação crítica não pode ser equivocadamente confundida com militância ou fundamentalismo, quando não se ensina a pensar, mas o que pensar;

5) de que a problematização e compreensão da História pode ser mais interessante ao estudante se mais próxima dele. Essa proposição pode ser um ponto de partida profícuo para o ensino de História, por várias razões, entre as quais: explora-se a historicidade e o contexto mais próximos do tema, com relações que vão 
muito além do local, mas que também o consideram, e o aluno pode compreender-se como agente histórico, que constrói, modifica ou mantém práticas e compreensões do mundo;

6) de que o processo de construção do conhecimento histórico deve ser gradativamente construído no ensino fundamental e médio como um todo, e que é viável inclusive como forma de superação do dilema quantidade (de conteúdo) versus qualidade de aprofundamento, problematização e construção desse aprendizado.

Entende-se que o ensino de História desenvolvido a partir desses pressupostos pode contribuir para a superação de muitos dilemas que este tem enfrentado, em especial quanto à sua função na sociedade e na escola contemporâneas, considerando-se que estas também carecem de reflexão. Assim, pode tornar-se mais significativo e interessante para alunos e professores, na medida em que estes não se vejam mais excluídos por uma História pronta e acabada, informativa, que pouco ou nada lhes auxilia para a compreensão de sua realidade. A proposição é de que a História pode permitir problematizar a realidade cotidiana, percebê-la como algo que não é natural, mas que foi constituído historicamente, e que, portanto, como agentes históricos que são, as escolhas que fazem - de ação ou omissão - constituem e contribuem para uma construção histórica, com desdobramentos a curto, médio e longo prazos.

\section{Dossiê didático temático Ditadura Civil- Militar no Paraná: procedimentos}

O desenvolvimento do dossiê ocorreu em duas fases semestrais. No primeiro semestre de 2009, foi lido e discutido o livro Enseñar a pensar historicamente: los archivos y las fuentes documentales en la enseñanza de la historia, de Gemma Traveria (2005), bem como o dossiê didático temático desenvolvido com base nessa proposta pelo Arquivo Nacional da Cataluña (VIDAL, 2005). 
No segundo semestre, foi definido o tema do dossiê a ser desenvolvido pelo GEEH: Ditadura Civil-Militar no Paraná. Os principais argumentos para sua escolha foram a ausência de uma problematização local, nos materiais didáticos disponíveis, sua presença obrigatória no ensino fundamental e médio e, ainda, a relativa facilidade em encontrar documentos para a composição do dossiê, bem como sua relevância para a compreensão da História contemporânea.

Em seguida, foi realizada uma pesquisa bibliográfica e foram estabelecidos temas e subtemas a serem contemplados: política, economia, sociedade, cultura e educação; e imprensa, censura/repressão, movimentos sociais, movimentos estudantis, Igreja e manifestações culturais. Em pesquisa realizada no Arquivo Público do Paraná e na Biblioteca Pública do Paraná, foram selecionados cerca de cem documentos, entre registros da Delegacia de Ordem Política e Social do Paraná e notícias de jornais.

Cada participante do grupo escolheu documentos e temas/subtemas de interesse e desenvolveu roteiros didáticos, compostos por um ou mais documentos, referências bibliográficas e sites relacionados, e atividades didáticas para a utilização dos documentos em sala de aula. Cada roteiro elaborado foi discutido coletivamente no GEEH, quantas vezes fossem necessárias, até sua aprovação.

O foco principal dos materiais foi o ensino médio. Contudo, na apresentação do dossiê buscou-se evidenciar a autonomia que o professor tem em utilizá-lo para o ensino fundamental, ou todo o roteiro, ou alguma atividade específica, ou, ainda, propor outros questionamentos a partir dos documentos - todos anexados ao dossiê. Além disso, embora os documentos se refiram ao Paraná, buscou-se problematizá-los de forma articulada com o contexto nacional, o que também permite que o dossiê seja utilizado em aulas de História em outros Estados. Finalmente, foram contemplados diferentes tipos de registros históricos, como documentos oficiais, depoimentos, fotografias e matérias de jornal.

A proposição do GEEH é a disponibilização do dossiê em seu site (www.gehistoria.ufpr.br) e a tentativa de publicá-lo, para distribuição a escolas públicas do Paraná. 


\section{Dossiê Ditadura Civil-Militar no Paraná: proposições didáticas}

Embora a apresentação das proposições didáticas perca um pouco de sua riqueza, por não ser possível no espaço deste artigo anexar os documentos utilizados na íntegra, nem contemplar todos os vinte roteiros que compõem o dossiê, neste tópico serão destacados alguns trechos e exemplos, com as problematizações trazidas nas atividades.

No roteiro intitulado "Sociedade e ditadura", o objetivo é "identificar e discutir a percepção de diferentes grupos sociais e instituições, no início da intervenção militar em 1964, e ao longo da ditadura”. A percepção positiva da ação militar em abril de 1964 é omitida na grande maioria dos livros didáticos, e é relevante para a compreensão daquele momento histórico, sem anacronismos ou reificações maniqueístas ou simplistas, uma vez que muitos indivíduos, grupos e instituições, além de não terem respostas homogêneas, também tiveram posturas diferentes ao longo da ditadura.

Neste roteiro didático, são reunidas dezesseis matérias de jornais de Curitiba - Gazeta do Povo e O Estado do Paraná - do período de 31 de março a 10 de abril de 1964, contemplando manifestações de João Goulart; do então governador paranaense, Ney Braga; da Câmara dos Deputados; de militares; de estudantes; da Igreja Católica; dos próprios jornais; além de dois depoimentos atuais de jornalistas, sobre como foi a percepção da intervenção militar naquele momento, e de quando e como ela foi mudando. Embora não seja possível transcrever todos os documentos, os títulos das matérias são bastante sugestivos:

1) Gazeta do Povo (31/03/64) - "Ney toma posição em defesa do regime e contra indisciplina";

2) O Estado do Paraná (01/04/64) - "Manifesto do Gal. Mourão Filho: Jango é chefe do governo comunista";

3) O Estado do Paraná (01/04/64) - "Jango afirma que as aspirações populares não podem ser reprimidas pela força";

4) O Estado do Paraná (01/04/64) - "Hora difícil"; 
5) O Estado do Paraná (01/04/64) - "PSD reage ante o processo de subversão: críticas à infiltração comunista no governo";

6) O Estado do Paraná (01/04/64) - "Bispos do Paraná lançam proclamação de alerta contra ameaça comunista";

7) Gazeta do Povo (02/04/64) - "Pela democracia";

8) Gazeta do Povo (02/04/64) - "JG falou à nação ontem à noite: posição";

9) Gazeta do Povo (02/04/64) - "Um Paraná calmo";

10) Gazeta do Povo (02/04/64) - "O nosso destino";

11) Gazeta do Povo (02/04/64) - "Reforma sim, mas não subversão";

12) Gazeta do Povo (02/04/64) - "Deputados apóiam a atitude do governador Ney Braga";

13) Gazeta do Povo (02/04/64) - "Estudantes apóiam posição em defesa do regime e da ordem";

14) Trecho de depoimento de Octavio Frias de Oliveira;

15) Trecho de depoimento de Luiz Alberto Ferreira Bahia;

16) Gazeta do Povo (09/04/64) - "Continua a Revolução";

17) Gazeta do Povo (09/04/64) - "Ação decisiva das Forças Armadas venceu a escravização do Brasil";

18) Gazeta do Povo (10/04/64) - "(Ato) Institucional visa consolidar o novo regime".

A primeira atividade proposta é a seguinte:

1. A ação militar que deu início à ditadura, entre 31 de março e 1 de abril de 1964, não foi necessariamente compreendida como golpe, naquele primeiro momento. Foi chamada de Revolução, pelos militares, mas também por grande parte da sociedade. Golpe e ditadura militar foram designações construídas e adotadas posteriormente, ao longo do período ditatorial e da permanência dos militares no poder, com o uso crescente de violência e repressão. Sobre o início da ditadura civil-militar no Brasil em 1964:

1.1. Leia como o seu livro didático explica como se chegou ao início dessa ditadura e faça pesquisas complementares sobre essa questão. Procure identificar o quadro político e social que precedeu ao golpe. 
1.2. Leia os documentos 2, 3, 8 e 18 e identifique os argumentos que João Goulart apresentava em sua defesa, e aqueles apresentados pelos militares, justificando sua intervenção.

1.3. Entreviste alguém que atualmente tenha mais de 60 anos de idade, sobre onde morava na época (cidade ou campo, capital ou interior), e o que lembra sobre esta ação militar (o início dela), como: de que forma ele(a) e sua família ficaram sabendo o que estava acontecendo? Quais eram os comentários sobre essa situação (favoráveis, desfavoráveis)? O que achavam de João Goulart e seu governo? Ele de fato era associado ao comunismo, e por quê? Qual era o sentimento em relação à ação militar - angústia, esperança, apatia, aprovação, reprovação, outros? Por quê?

1.4. Em grupo, sistematizem as informações das atividades 1.2 e 1.3 e discutam: considerando o contexto e os argumentos identificados na imprensa e nas entrevistas, para uma pessoa da época

Com esse conjunto de atividades, o propósito é instigar o aluno a pensar sobre aquele momento, comparando a versão apresentada no livro didático e a percepção de pessoas comuns sobre o mesmo fato. Dessa forma, podem ser identificadas convergências e divergências, e ao professor caberia a problematização acerca dessas distintas versões, inclusive sobre por que determinada explicação é predominante nos livros didáticos em detrimento de outras.

Essa preocupação é aprofundada na atividade seguinte, na qual os documentos devem ser distribuídos aos alunos, para que identifiquem a pessoa, o grupo ou a instituição que se manifesta, e os argumentos favoráveis e desfavoráveis à intervenção militar em abril de 1964. Em seguida, os argumentos devem ser reunidos, verificando-se os mais recorrentes, e deve-se discutir sua relação com o contexto abordado na Atividade 1. Na sequência:

2.2. Muitos desses agentes - pessoas, grupos ou instituições - modificaram sua opinião e atitude, à medida que os militares mudavam seu discurso e suas ações. Cada grupo deve escolher um deles: imprensa, movimento estudantil, Igreja católica, entre outros, e pesquisar, ao longo da ditadura militar a) como foi sua relação e atitude frente à ditadura, b) as formas e estratégias que utilizou para organizar-se e 
manifestar-se como opositor ou apoiador, e c) as conseqüências de tais ações. Cada grupo deve apresentar os resultados obtidos para a turma, para discussão.

Com essa atividade, além dos grupos desenvolverem pesquisa que pode ocorrer a partir do livro didático, mas que necessariamente deve envolver outras referências -, busca-se permitir a reflexão sobre a ditadura ao longo das duas décadas e relacionar as ações e estratégias dos militares e de outros agentes históricos, individuais ou coletivos, ao contexto.

Outra preocupação desse mesmo roteiro é a compreensão do cotidiano daquele período, uma vez que bem pouco aparece em livros didáticos. Nesse sentido, propõe-se o seguinte encaminhamento:

3. Assista ao filme "O ano em que meus pais saíram de férias" (2006). A história se passa em 1970, no bairro do Braz, na cidade de São Paulo. Neste ano, além do arrefecimento da ditadura militar, após o AI-5 (1968), o time brasileiro participava da Copa do Mundo, e a economia crescia forte (o milagre econômico). Antes de assistir ao filme, seria importante ler um pouco sobre esse contexto.

Observe e anote, sobre o filme, os seguintes elementos:

- hábitos, objetos e práticas cotidianas daquela época, por exemplo: transportes, organização e utilização das ruas, vestuários, brincadeiras e brinquedos, televisão e rádio, produtos (materiais e culturais) consumidos, relações familiares, valores e crenças, entre outros;

- se há menção, direta ou indireta, ao AI-5 ou à censura e repressão da ditadura;

- como os diferentes personagens (escolha ao menos três deles) agem, em relação à ditadura militar (se sabem o que está acontecendo, se manifestam-se ou conversam sobre isso, qual sua reação, se de apoio, de omissão, de enfrentamento, de busca por sobreviver sem ser incomodado, entre outros);

- a repressão pelo regime militar;

- a utilização da euforia relacionada à Copa do Mundo, pela ditadura; e - outros elementos que chamarem a atenção, relacionados ao tema.

3.1. Com base em suas anotações, redija um relatório sobre o filme, abordando as questões acima indicadas. 
3.2. Em grupo, comparem seus registros, e com base em indícios trazidos pelo filme e nas informações discutidas nas atividades anteriores, escolham um tema ou questão que julgarem mais interessante e construam uma matéria de jornal, como se fossem um jornalista da época (1970), apoiando ou questionando a ditadura. Em seguida, desenvolvam o título e o texto da matéria (20 a 30 linhas). O jornalista deve explicar porque é favorável ou contrário à ditadura, e pode usar depoimentos, imagens, ou outras fontes para a composição da notícia e para subsidiar sua abordagem ao tema.

3.3. Cada grupo deve apresentar a matéria para a turma, para discussão, e as notícias devem ser reunidas para constituírem dois jornais: um de apoio e um de oposição à ditadura.

3.4. Em seguida, cada grupo deve sistematizar quais os principais argumentos que apareceram em seu jornal, contrários ou favoráveis à ditadura.

3.5. A partir desse material, o professor coordenará um júri simulado, em que a ditadura civil-militar está sendo julgada, e os argumentos da acusação e da defesa serão apresentados e debatidos.

De acordo com o enunciado nos fundamentos teórico-metodológicos, um dos propósitos do dossiê é a utilização e problematização de documentos históricos para que as dimensões formativas relativas ao conteúdo específico e ao desenvolvimento de competências e habilidades possam ser contempladas, conjunta e simultaneamente. Nessa última atividade, são abordadas diferentes dimensões de um mesmo contexto e diversos níveis de questionamentos das informações, visando a que os alunos possam tanto compreender o contexto em sua complexidade, superando maniqueísmos e anacronismos comuns ao tema, quanto desenvolverem um posicionamento mais crítico em relação a fontes de informação e a documentos - sejam os apresentados no dossiê, sejam outros que venham a encontrar, generalizando a aplicação dos procedimentos de leitura, contextualização, análise e crítica propostos para outras questões e períodos históricos.

Nos demais roteiros didáticos, são contempladas discussões conceituais - como democracia, ditadura, golpe militar, revolução -, além 
de outros temas, como os Atos Institucionais, o comunismo, órgãos de controle e repressão, reformas educacionais, de forma que as proposições se articulam e complementam, evidenciando múltiplas possibilidades de abordagem sobre aquele contexto.

\section{Considerações finais}

O desenvolvimento do dossiê, de forma coletiva, propiciou aos participantes - professores em exercício e graduandos em História - a oportunidade de exercitarem o olhar e a elaboração de atividades que permitissem o uso didático de documentos. Para tanto, a discussão teórico-metodológica que precedeu esse exercício foi fundamental, no sentido de, inclusive, ser testada, tanto em sua validade e viabilidade quanto em relação a ser apropriada de fato pelos participantes, na tão necessária articulação entre teoria e prática. Por outro lado, ao participarem por um ano de atividades quinzenais de estudo, produção e discussão sobre fundamentos teórico-metodológicos do ensino de História e uso didático de documentos, sobre Ditadura Civil-Militar no Paraná e sobre produção de materiais didáticos a partir de documentos, a experiência constituiu-se em uma formação continuada de fato.

A diversidade de temas, documentos e problematizações proposta é indicador das possibilidades de abordagem do tema em sala de aula, embora se tenha clareza de que dificilmente o dossiê venha a ser utilizado na íntegra. Essa constatação decorre ainda dos dilemas postos à escola e mais especificamente ao professor, em relação principalmente ao tempo escolar, ao cronograma e à seleção dos conteúdos a serem contemplados.

De forma alguma essa situação é compreendida como um demérito para o dossiê, uma vez que é certa a contribuição que ele traz, tanto na disponibilização de documentos, que embora públicos nem sempre são acessíveis ao professor, quanto na problematização de diversos aspectos do tema, sob olhares, questionamentos e tempos distintos. De posse do dossiê, cada professor pode optar por utilizar os roteiros, documentos, 
atividades e referências complementares, de forma que, com conhecimento e criatividade, possa buscar caminhos para tornar o tema interessante para seus alunos, ou seja, que faça sentido e contribua para que estes compreendam melhor a constituição da realidade brasileira, especificamente no período da Ditadura Civil-Militar.

\section{Referências}

BOURDIEU, P. Coisas ditas. São Paulo: Brasiliense, 2004.

CITRON, S. Ensinar a história hoje: a memória perdida e reencontrada. Lisboa: Livros Horizonte, 1990.

PERRENOUD, P. O trabalho sobre o habitus na formação de professores: análise das práticas e tomadas de consciência. In: PAQUAY, L. et al. (Org.). Formando professores profissionais: quais estratégias? Quais competências? 2. ed. Porto Alegre: Artmed, 2001. p. 161-184.

TRAVERIA, G. T. Enseñar a pensar historicamente: los archivos y las fuentes documentales em la enseñanza de la historia. Barcelona: I.C.E. Universitat Barcelona; Horsori Editorial, 2005.

VIDAL, M. P. R. Solidaris en defensa de la llibertat: refugiats de guerra a Catalunya (1936-1939). Catalunya: Arxiu Nacional de Catalunya, 2005.

Recebido: 17/05/2010

Received: 05/17/2010

Aprovado: 10/10/2010

Approved: 10/10/2010 